\title{
DNA methylation in the APOE gene: its link with Alzheimer's and cardiovascular health
}

\author{
Jure Mur ${ }^{a, b}$, Daniel L. McCartney ${ }^{b}$, Rosie M. Walker ${ }^{b}$, Archie Campbell ${ }^{b}$, \\ Mairead L. Bermingham ${ }^{b}$, Stewart W. Morris ${ }^{b}$, David J. Porteous ${ }^{b}$, Andrew M. \\ Mclntosh $^{\text {b,c }}$, Ian J. Deary ${ }^{a}$, Kathryn L. Evans ${ }^{\text {b,1 }}$, Riccardo E. Marioni ${ }^{b, 1, *}$
}

\section{Abstract}

Genetic variation in the apolipoprotein E (APOE) gene is associated with Alzheimer's disease (AD) and risk factors for cardiovascular disease (CVD). DNA methylation at APOE has been linked to altered cognition and AD. It is unclear if epigenetic marks could be used for predicting future disease. We assessed blood-based DNA methylation at $13 \mathrm{CpGs}$ in the APOE gene in 5828 participants from the Generation Scotland (GS) cohort. Using linear regression, we examined the relationship between $A P O E$ methylation, cognition, cholesterol, and the risks for $A D$ and $C V D$. DNA methylation at two $C p G s$ was associated with the ratio of total-toHDL cholesterol, but not with cognition, or the risks of AD or CVD. APOE methylation could be involved in the levels of blood cholesterol, but there is no evidence for the utility of $A P O E$ methylation as a biomarker for predicting AD or CVD.

\footnotetext{
${ }^{a}$ Department of Psychology, University of Edinburgh, Edinburgh, UK.

${ }^{b}$ Centre for Genomic and Experimental Medicine, Institute of Genetics and Molecular Medicine, University of Edinburgh, Edinburgh, UK.

${ }^{\mathrm{c}}$ Division of Psychiatry, Centre for Clinical Brain Sciences, University of Edinburgh, Edinburgh, UK.

${ }^{1}$ Co-sharing senior authors.

* Corresponding author. Email: riccardo.marioni@ed.ac.uk; Tel: +44 (0)131 6518528.
} 


\section{Introduction}

\subsection{The APOE gene}

The apolipoprotein $\mathrm{E}(A P O E)$ gene is located on chromosome 19, with two SNPs in its fourth exon defining three alleles, $\varepsilon 2, \varepsilon 3$, and $\varepsilon 4$, resulting in the production of three isoforms of the apoE protein, apoE2, E3, and E4 [1]. The APOE $\varepsilon 4$ genotype is a well-known risk factor for Alzheimer's disease (AD) [2,3] and a prominent candidate in cardiovascular research $[4,5]$. The protein is expressed in various tissues, including the brain [6]. It acts as a ligand for members of the low-density lipoprotein (LDL) receptor family and is involved in the clearance of lipoproteins and cholesterol from the circulatory system $[7,8]$.

APOE exhibits an allele-specific association with risk of AD. Possession of the $\varepsilon 4$-allele confers an increased risk, while the $\varepsilon 2$-allele is protective [2]. The isoforms of apoE differ in their binding-affinity for lipoproteins and LDL-receptors, and differentially influence levels of serum cholesterol [9]. The E2-variant reduces the levels of total- and LDL-cholesterol, while the E4 variant raises them [6]. However, the connection between APOE and cardiovascular disease (CVD) is less robust. While there is some evidence for an increased risk of CVD-related death in carriers of the $\varepsilon 4$-allele [1], this has not always been observed [10].

\section{2. $A P O E$ methylation in $A D$ and $C V D$}

Epigenetic modifications have been associated with many human disorders [11]. DNA methylation is the addition of a methyl group to the 5-position of cytosine in the context of a cytosine-guanine dinucleotide (CpG; [12]). Many studies have found a link between AD and methylation $[12,13]$. Candidate gene studies for $A P O E$ have shown that methylation in this 
gene is associated with dementia $[14,15,16,17]$ with neuritic amyloid plaque burden [18], and with cognitive ability [19].

Associations have been suggested between epigenetic mechanisms and risk factors for cardiovascular disease $[20,21,22,23]$. Whereas a recent systematic review identified 34 candidate-gene studies on methylation in CVD [4], few have explored modifications in $A P O E$, and there have been some conflicting results: while Karlsson et al. [15] found no evidence for differences in APOE methylation in blood between patients with CVD and healthy controls, Ji et al. [24] reported $A P O E$ hypermethylation in the blood of patients with coronary heart disease compared to controls.

To help clarify this role of $A P O E$, we utilize data from Generation Scotland, a large populationbased cohort, the size of which is several times greater than samples in previous studies, providing a robust analysis of $A P O E$ methylation and cognitive and vascular health. We characterise blood-based methylation in the promoter region, $2^{\text {nd }}$ and $3^{\text {rd }}$ exons and introns, and $4^{\text {th }}$ exon of the $A P O E$ gene, and explore links between $A P O E$ methylation and a variety of markers of cognitive function, $A D$, vascular health, and CVD. Due to the importance of developing new clinical biomarkers for health outcomes before the onset of disease, we restrict our sample to ages between 30 and 65 years.

\section{Methods}

\subsection{The sample}

Generation Scotland (GS; $[25,26])$ is a family-based cohort of over 22,000 individuals from Scotland (aged 18-99 years) that were genotyped and extensively phenotyped during the 
baseline assessment between the years 2006 and 2011. Blood-based genome-wide DNAmethylation were generated in 9551 individuals as part of the sub-study Stratifying Resilience and Depression Longitudinally (STRADL; [27]).

\subsection{Methylation and $A P O E$ measurements}

DNA methylation in peripheral blood samples was profiled in two sets (Set $1: n=5,087$ in 2017 and Set 2: $n=4,450$ in 2019), using the Illumina HumanMethylationEPIC BeadChip as described previously [28]. Briefly, low quality samples, probes with low detection rates, and participants for which the predicted sex did not match the recorded sex were excluded (Supp.

\section{Methods 1).}

We removed related participants from Set 1 using a genetically determined relationship cutoff of >0.05 (GCTA GREML; [29]) to reduce the potential influence of shared genetics on the findings. The participants in Set 2 were unrelated to each other and to those in Set 1 . We restricted the analysis to CpGs located on chromosome 19 between 45,409,039 $45,412,650 \mathrm{bp}$, which corresponded to the region encompassing the APOE-gene (UCSC GRCh37/hg19 genome build). To restrict the age of our sample, we removed participants younger than 30 years and older than 65 years. After combining the two sets, our final sample consisted of a total of $13 \mathrm{CpGs}$ in 5,828 participants (Supp. Figure 1).

APOE-haplotype status was determined using Taqman technology at the Clinical Research Facility, Western General Hospital, Edinburgh. Based on the identity of the nucleotides at SNPpositions rs429358 and rs7412, participants with the $\varepsilon 3 / \varepsilon 3$-haplotype were classified as $\varepsilon 3$ carriers, participants with the $\varepsilon 2 / \varepsilon 2$ - and $\varepsilon 2 / \varepsilon 3$-haplotypes were classified as $\varepsilon 2$-carriers, and 
participants with the $\varepsilon 3 / \varepsilon 4-$ and $\varepsilon 4 / \varepsilon 4$-haplotypes were classified as $\varepsilon 4$-carriers. The 126 participants (2.2\%) with the $\varepsilon 2 / \varepsilon 4$-genotype were not included in analyses in which carrierstatus was implemented as a variable.

\subsection{Characterisation of APOE methylation}

We examined the methylation status of $13 \mathrm{CpGs}$ in the $A P O E$ gene (Figure $1 \mathrm{~A})$. Twelve CpGs exhibited similar methylation levels to those previously described (Supp. Table 1; $[15,16,22]$ ), whereas one of them (cg20051876, which is unique to the Illumine EPIC array) had not been reported before. Based on the Illumina-annotated locations of the CpGs on the chromosome, their relative distances to each other, and their methylation levels, the $\mathrm{CpGs}$ were classified into three groups: hypermethylated (each site $>50 \%$ mean methylation) and lying in the promoter region (region 1: cg20051876, cg14123992, cg04406254), hypomethylated (each site $<50 \%$ mean methylation) and lying in the region encompassing the first two exons and introns (region 2: cg26190885, cg12049787, cg08955609, cg18768621, cg19514613, cg06750524), and hypermethylated and lying in the $4^{\text {th }}$ exon (region 3: cg16471933, cg05501958, cg18799241, cg21879725).

\subsection{Cognitive variables}

Four measures of cognitive function [26] were evaluated: (1) the Wechsler digit symbol test as a measure of the speed of information processing, (2) the letter-based $(C, F, L)$ phonemic verbal fluency test as a measure of executive function, (3) the Mill Hill Vocabulary test (combined junior and senior synonyms) as a measure of crystallised ability, and (4) the 
Wechsler immediate and delayed Logical Memory tests (one story) as a measure of verbal declarative memory. Participants with a zero-value were judged as resulting from nonparticipation and were recorded as missing. A measure of global cognitive function (cognitiveg) was derived by applying principal component analysis (PCA) to the four cognitive measures, with cognitive-g defined as the first unrotated principal component. This factor explained $44 \%$ of the total variance from all four cognitive measures, with loading values ranging between 0.47 and 0.53 .

\subsection{Approximations for the risk of $A D$ and of $C V D$}

Only three participants reported having AD, and 203 participants (3.5\%) reported having CVD. We therefore created approximate measures of risk that were based on reports by participants about these illnesses for close relatives (parents, siblings, and grandparents). For both $A D$ and CVD, each relative was assigned either 0 or 1 ( 0 : absence of the disorder, 1 : presence of the disorder) based on the report of the participant. To derive each risk measure, we calculated the weighted sums of family records for each participant as follows:

$$
\text { risk }=0.5 \times(\text { mother }+ \text { father }+ \text { sister }+ \text { brother })+0.25 \times(\text { either grandparent })
$$

The choice of weights used for a given family member was based on kinship/relatedness between that relative and the participant. The participants that self-reported as having AD or CVD were excluded from the models that included the risk of $A D$ or the risk of CVD as predictor variables, respectively. Due to a low number of relatives with $A D$ and a consequential skew in the distribution of AD-risk, AD-risk was transformed into a categorical variable AD-class (low risk: no close relatives with $A D, n=4854$; high risk: at least one close relative with $A D, n=$ 974). For cholesterol levels, the total-to-HDL ratio was used. 


\subsection{Covariates}

For alcohol consumption, we did not include participants that have quit drinking $(n=373)$ or whose answers relating to recent alcohol consumption according to their own assessment did not correspond to their usual drinking pattern $(n=1557)$. Information on smoking was processed as described previously [30]; we did not include participants that have quit smoking ( $n=673$ ). The sample sizes for the fully-adjusted models (see below) thus depended on the included covariates with missing values. Smoking was assessed in pack years and alcohol consumption in units per week. Activity levels were recorded in minutes per week; two different versions of the questionnaire were used in the study, with each participant completing only one of them. We therefore combined the two versions so that the responses by all participants were on the same scale (Supp. Methods 2).

\subsection{Statistical analysis}

For all numerical variables, outliers - defined as scores beyond four interquartile ranges from the median - were excluded. For each analysis, linear mixed models were built. For each CpG (outcome), two models were run: (1) a basic-adjusted model containing the primary predictor variables as defined in the hypothesis and (2) a fully-adjusted model that included additional covariates:

Basic-adjusted model:

$$
\begin{gathered}
\text { methylation } \sim \text { predictor }+C D 4+N K+\text { Bcell }+ \text { Mono }+ \text { Gran }+(1 \mid \text { plate processing batch }) \\
+ \text { testing set }
\end{gathered}
$$

Fully-adjusted model: 


$$
\begin{aligned}
& \text { methylation } \sim \text { predictor }+C D 4+N K+\text { Bcell }+ \text { Mono }+ \text { Gran }+(1 \mid \text { plate processing batch }) \\
& + \text { testing set }+ \text { age }+ \text { sex }+ \text { smoking }+ \text { drinking }+ \text { education }+ \text { deprivation index } \\
& \quad+\text { predictor }- \text { specific covariates }
\end{aligned}
$$

The predictor-specific covariates used in the fully-adjusted model varied according to the predictor variable of the model and, whenever possible, corresponded with previous studies $[15,22]$. Both the basic- and the fully-adjusted model included as covariates the batch in which the samples of a given participant were processed on the array (fitted as a random effect on the intercept) and the estimated proportions of CD8+- and CD4+- T-cells, natural killer cells, B cells, monocytes, and granulocytes. Cell composition correction controls for the fact that DNA methylation patterns can be confounded by the heterogeneity of cells in the tissue used for analysis [31].

The threshold for statistical significance was Bonferroni-corrected for each CpG. All continuous variables (except the variable age when used as a predictor) were transformed to have a mean of 0 and a standard deviation of 1 . When the predictor was a categorical variable, analysis of variance was performed, comparing the model of interest with the same model excluding the predictor variable.

All statistical analyses were performed in $\mathrm{R}$.

\section{Results}

\subsection{Sample characteristics}

Among the 5828 participants, 3399 (58.3\%) were female and 2429 (41.7\%) were male. The age range was $30-65$ years and the mean age was 52.7 years (Table 1 ). APOE genotype 
frequencies were comparable to those described previously for the British population (Table 1; $[10,32])$. Correlations between DNA methylation levels in blood (this study) and brain tissue (publicly available datasets) for the $13 \mathrm{CpGs}$ in this study ranged from -0.30 to 0.51 for the whole brain (IMAGE-CpG: https://han-lab.org/methylation/default/imageCpG, [33], last accessed 13.10.2019), from -0.26 to 0.40 for Brodmann area 20 (BECon: https://redgar598.shinyapps.io/BECon/, [34], last accessed 13.10.2019), and from -0.21 to 0.20 for the entorhinal cortex (https://epigenetics.essex.ac.uk/bloodbrain/, [35], last accessed 13.10.2019), with most CpGs exhibiting low correlations between brain- and blood methylation (Supp. Table 1).

\subsection{Association between CpGs}

The correlations in methylation for all pairwise combinations between the $13 \mathrm{CpGs}$ ranged from -0.49 to 0.78 , with a mean absolute correlation of 0.32 (Figure $1 B$ ). After correcting for multiple comparisons, $68 / 78$ correlations were statistically significant at $p<6.4 \times 10^{-4}$ (=0.05/78), with $38(60 \%)$ positive, and $30(40 \%)$ negative. CpGs within a region tended to be methylated to a similar extent: all significant correlations among CpGs within region 1 (3/3, $100 \%)$ and within region $3(6 / 6,100 \%)$, and most of the significant correlations among CpGs within region $2(11 / 13,85 \%)$ were positive. Moreover, there was a tendency for CpGs in regions 2 and 3 to be methylated in opposite directions: most of the significant correlations $(17 / 22,77 \%)$ were negative. In contrast, regions 1 and 3 tended to be methylated in the same direction, with all significant correlations $(12 / 12,100 \%)$ positive. 


\subsection{Association between methylation and genotype}

After correcting for multiple testing, there was evidence for an association between $A P O E$ carrier-status and DNA methylation at five CpGs in the fully-adjusted models: cg14123992 $\left(\eta^{2}=0.003, p=3.9 \times 10^{-4}\right), \operatorname{cg} 04406254\left(\eta^{2}=0.004 p=4.0 \times 10^{-6}\right), \operatorname{cg} 06750524\left(\eta^{2}=0.022, p=8.6 \times 10^{-}\right.$ $\left.{ }^{16}\right), \operatorname{cg} 16471933\left(\eta^{2}=0.014, p=2.4 \times 10^{-16}\right)$, and $\operatorname{cg} 21879725\left(\eta^{2}=0.003, p=1.3 \times 10^{-4}\right)$ (Figure 2, Supp. Table 2). Post-hoc testing between the APOE groups showed that at all five $\mathrm{CpGs}$ the associations were due to higher methylation levels in $\varepsilon 4$ carriers compared to $\varepsilon 3$ carriers.

\subsection{Age-dependent drift in DNA-methylation}

In the basic-adjusted model, 7/13 CpGs showed an association with age after correction for multiple testing ( $\mathrm{R}^{2}$ range: $4.0 \times 10^{-5}-0.03$; Supp. Table 3 ). Three $\mathrm{CpGs}$ remained significant after correction for multiple testing in the fully-adjusted model (Figure 3, Supp. Table 3). Most CpGs within a region exhibited the same direction of change with respect to aging. CpGs in the generally hypomethylated region 2 tended to have greater methylation with older age, whereas CpGs in the generally hypermethylated regions 1 and 3 tended to have lower methylation with older age. None of the CpGs in our analyses were in a list of age-related variable methylated positions (aVMPs; [36]). However, the Breusch-Pagan test for heteroscedasticity indicated non-random variation in the residuals by age for all CpGs in both the basic- and the fully-adjusted models (Supp. Table 4).

\subsection{APOE methylation and cognitive function}

We observed no association between general cognitive ability and DNA methylation in the fully-adjusted regression models after correction for multiple testing (Supp. Table 5). There 
were associations between the individual cognitive tests and DNA methylation levels in the basic- but not fully-adjusted regression models (Supp. Table 6).

\section{6. $A P O E$ methylation and the risk of $A D$}

To determine whether carrier-status was associated with AD-class (0: absence of the disorder,

1: presence of the disorder), a logistic regression was run, with AD-class as the outcome variable and carrier-status as the predictor. We observed no associations between DNA methylation levels and AD-risk in the basic- or fully-adjusted models after correcting for multiple testing (Supp. Table 7). The Wald Chi-Squared test confirmed a general effect of carrier-status in the basic-adjusted model $\left(\chi^{2}=49.8, p=8.9 \times 10^{-11}\right)$ and in the fully-adjusted model $\left(\chi^{2}=33.4, p=2.6 \times 10^{-7}\right)$. The $\varepsilon 4$-allele was significantly associated with the high-risk ADclass both in the basic- $\left(\mathrm{OR}=1.70, \mathrm{p}=3.2 \times 10^{-11}\right)$ and fully-adjusted models

$\left(\mathrm{OR}=1.77, p=1.2 \times 10^{-7}\right)$

\section{7. $A P O E$ methylation and the risk of CVD}

We observed no association between APOE methylation and the risk measure of CVD, nor was there an association between APOE genotype and the risk measure of CVD (Supp. Table 8). However, $A P O E$ genotype was linked to the total-to-HDL cholesterol ratio in the fullyadjusted model $\left(\chi^{2}=68.5, p=1.3 \times 10^{-15}\right)$. Specifically, both the $\varepsilon 2$ - and $\varepsilon 4$-carriers differed in the ratio of total-to-HDL cholesterol compared to $\varepsilon 3$-carriers in the fully-adjusted model ( $\varepsilon 2$ : estimate $=-0.22, \mathrm{SE}=0.048, \mathrm{p}=6.4 \times 10^{-6} ; \varepsilon 4$ : estimate $\left.=0.21, \mathrm{SE}=0.036, \mathrm{p}=1.2 \times 10^{-8}\right)$. The ratio of total-to-HDL cholesterol was significantly associated with methylation levels after 
correcting for multiple testing at three CpGs in the fully-adjusted models: cg08955609, cg18768621, and cg16471933 (Supp. Table 9). Due to the strong association between APOE genotype and cholesterol levels, the fully-adjusted model was rerun with APOE-genotype as covariate; $\operatorname{cg} 08955609$ (estimate $=-0.065, \mathrm{SE}=0.019, \mathrm{p}=6.7 \times 10^{-4}$ ) and $\operatorname{cg} 18768621$ (estimate=0.059, $\mathrm{SE}=0.017, \mathrm{p}=4.3 \times 10^{-4}$ ) remained statistically significant (Figure 4, Supp. Table 9). The validity of CVD-risk as a risk measure for CVD was confirmed by running a linear regression model, with self-reported CVD as an outcome measure and CVD-risk as a predictor variable, with covariates as in the fully-adjusted model above (estimate $=0.02$, error $=0.0032$, $\left.p=2.1 \times 10^{-11}\right)$

\section{Discussion}

\subsection{Correlations between CpGs and age-drift in methylation}

In this study, we used DNA methylation- and phenotypic data from a large cohort, Generation Scotland, to explore methylation in the $A P O E$ gene and its association with risk factors for $A D$, CVD, and blood cholesterol.

We observed correlations among CpGs which had been reported before [19]. Compared with Liu et al. [19], the correlations observed in our study were stronger and more of them were negative. In contrast to the findings of Karlsson et al. [15], the methylation levels of five CpGs correlated with carrier-status for the different $A P O E$ alleles. This difference may be due to the increased power of our study over that of Karlsson et al. [15].

We replicated a finding by Ma et al. [22] of age-drift in methylation in the APOE gene: 3/13 CpGs showed age-dependent changes. In each hypermethylated CpG, methylation levels 
tended to decrease with age, while in each hypomethylated $\mathrm{CpG}$, methylation levels tended to increase with age. All CpGs exhibited heteroscedasticity for the change in methylation as a function of age, demonstrating that the drift could be due to increases in methylomic variability with increasing age.

\subsection{Relationship between $A P O E$ methylation, $A D$ and cognition}

Neither cognition, nor family history of AD were associated with APOE methylation. This might be due to a lack of appreciable changes in APOE methylation before the onset of symptoms of $A D$. Most previous studies that linked differential APOE methylation with $A D$ were conducted on tissue from patients that had either been screened positive for cognitive dysfunction [15], or diagnosed with $A D[14,16,17]$; only one study [19] evaluated the relationship between DNA methylation and cognition in healthy participants. The epigenetic changes in $A P O E$ accompanying AD-related cognitive decline could result from the pathophysiology of the disorder or from adaptive responses of the organism as a result of AD, neither of which may be present at appreciable levels in the population studied here. Another consideration concerns the tissue used. Foraker et al. [14] used post-mortem brain-tissue, Karlsson et al. [15] and Liu et al. [19] used blood, while Shao et al. [16] and Wang et al. [17] used both. In fact, the latter were not able to replicate their findings from brain-tissue in blood. Blood represents an attractive medium for identifying biomarkers for disease. Indeed, it has been reported that patients with $A D$ and healthy controls can be distinguished based on gene-expression patterns in blood [37]. However, the APOE gene is differently expressed between brain tissue and blood $[16,17]$ and $A P O E$ CpGs exhibit relatively modest correlations between blood- and brain methylation $[33,34,35]$. Thus, blood-methylation may exhibit AD- 
associated changes that are distinct from methylation changes in the brain or they might appear later in the course of the disorder. Finally, while some studies have reported ADassociated changes in $A P O E$ methylation as described above, little research has been done on the topic and few - if any - replication studies have been performed to validate the effects. Moreover, some prominent studies that investigated associations between DNA methylation and $A D$ across the entire genome did not report $A P O E$ to be altered in the disorder $[13,38]$.

\subsection{Relationship between APOE methylation and blood cholesterol}

We did not replicate the finding [24] of an association between APOE methylation and CVD; our results are in line with reports by Karlsson et al. [15] and Sharma et al. [39]. However, we did find a negative association between $A P O E$ methylation and the ratio of the total to HDLcholesterol at cg08955609 and cg18768621; a finding that - to our knowledge - had not been reported before. Our measurements of cholesterol provide only levels of total blood cholesterol and of HDL cholesterol. Because of this - especially considering the opposite correlation of APOE genotype with the concentrations of LDL and VLDL, respectively [40] - it is not possible to assess the relationship between methylation and the individual components of blood cholesterol.

\subsection{Limitations and future directions}

The results of the present study offer additional insight into the epigenetics of the APOE gene and its association with relevant phenotypes. The main strength of the study is the large sample size from a relatively representative sample of the Scottish population. Nevertheless, 
we recognize several limitations. Firstly, the measures of risk for $A D$ and CVD were inferred from information on participants' relatives. The rough approximation of risk underestimates the importance of environmental factors. Moreover, different participants in our cohort have different numbers of relatives. Secondly, the study is limited to (a subset of) the methylome; other important epigenetic mechanisms that are currently less accessible to analysis at scale might also play important roles in the studied interactions. Thirdly, our study is based on methylation data from the blood, which for most CpGs correspond to methylation patterns in the brain. This might preclude the identification of potential epigenetic changes prior to disease onset and allows only limited insight into underlying biological processes. However, due to the multitude of peripheral biological processes associated with $A D$, blood may be a legitimate tissue for DNA methylation studies. Finally, this study adopts a candidate gene approach; while $A P O E$ is a biologically plausible candidate for implications in AD and CVD, genome-wide approaches may inform on the relative importance of $A P O E$.

In conclusion, we showed that CpGs in the APOE gene exhibit correlations within- and between distinct regions of the gene and that the methylation levels at some CpGs of the $A P O E$ gene correlate with the $A P O E$ genotype. Furthermore, we found an association between methylation level at cg8955609 and cg18768621, and blood cholesterol. We did not find differences in the levels of $A P O E$ methylation between individuals at low risk and individuals at high risk of developing either AD or CVD. Future work might explore longitudinal changes in methylation as it relates to adverse health outcomes to circumvent the problems of the present study and improve our understanding of the exact timing of epigenetic changes in $A D$ and CVD. 


\section{Acknowledgements}

GS received core support from the Chief Scientist Office of the Scottish Government Health Directorates (CZD/16/6) and the Scottish Funding Council (HR03006). Genotyping and DNA methylation profiling of the GS samples was carried out by the Genetics Core Laboratory at the Clinical Research Facility, University of Edinburgh, Edinburgh, Scotland and was funded by the Medical Research Council UK and the Wellcome Trust (Wellcome Trust Strategic Award "STratifying Resilience and Depression Longitudinally" ([STRADL; Reference 104036/Z/14/Z]). DLM and REM are supported by Alzheimer's Research UK major project grant ARUK-PG2017B10. IJD is a member of the Lothian Birth Cohorts group at the University of Edinburgh and is supported by Age UK (Disconnected Mind grant), the Medical Research Council (MR/R024065/1), and the USA's National Institutes of Health (1RO1AG054628-01A1). JM is supported by funding from the Wellcome Trust 4-year PhD in Translational Neuroscience training the next generation of basic neuroscientists to embrace clinical research [108890/Z/15/Z]. 
bioRxiv preprint doi: https://doi.org/10 1101/811224; this version posted October 21 2019. The copyright holder for this preprint (which was not certified by peer review) is the author/funder, who has granted bioRxiv a license to display the preprint in perpetuity. It is made available under aCC-BY-NC-ND 4.0 International license.

\section{Tables and figures}

Figure 1: Structure of the $A P O E$ locus and the location of $\mathrm{CpGs}(\mathbf{A})$, and correlations among $\mathrm{CpGs}$ in the $A P O E$ gene (B). A: The top panel shows the chromosomal location of the APOE gene; the second panel represents the location on the chromosome in $\mathrm{kb}$; the third panel shows the structure of the APOE gene, with exon-regions thickened. The approximate locations of $\mathrm{CpGs}$ on the APOE gene is indicated by the arrows, with colours representing regional classification: region 1 (orange), region 2 (green), or region 3 (blue). B: The strength of the correlation is represented by a colour code, ranging from dark red (strong negative correlation) to dark blue (strong positive correlation). The colour of the text denotes the location for a given $\mathrm{CpG}$ on the APOE gene: region 1 (orange), region 2 (green), or region 3 (blue).

A

\begin{tabular}{|c|c|c|c|c|c|}
\hline & & 13 & & & \\
\hline 45,408 & 45,409 & 45,410 & 45,411 & 45,412 & 45,413 \\
\hline
\end{tabular}
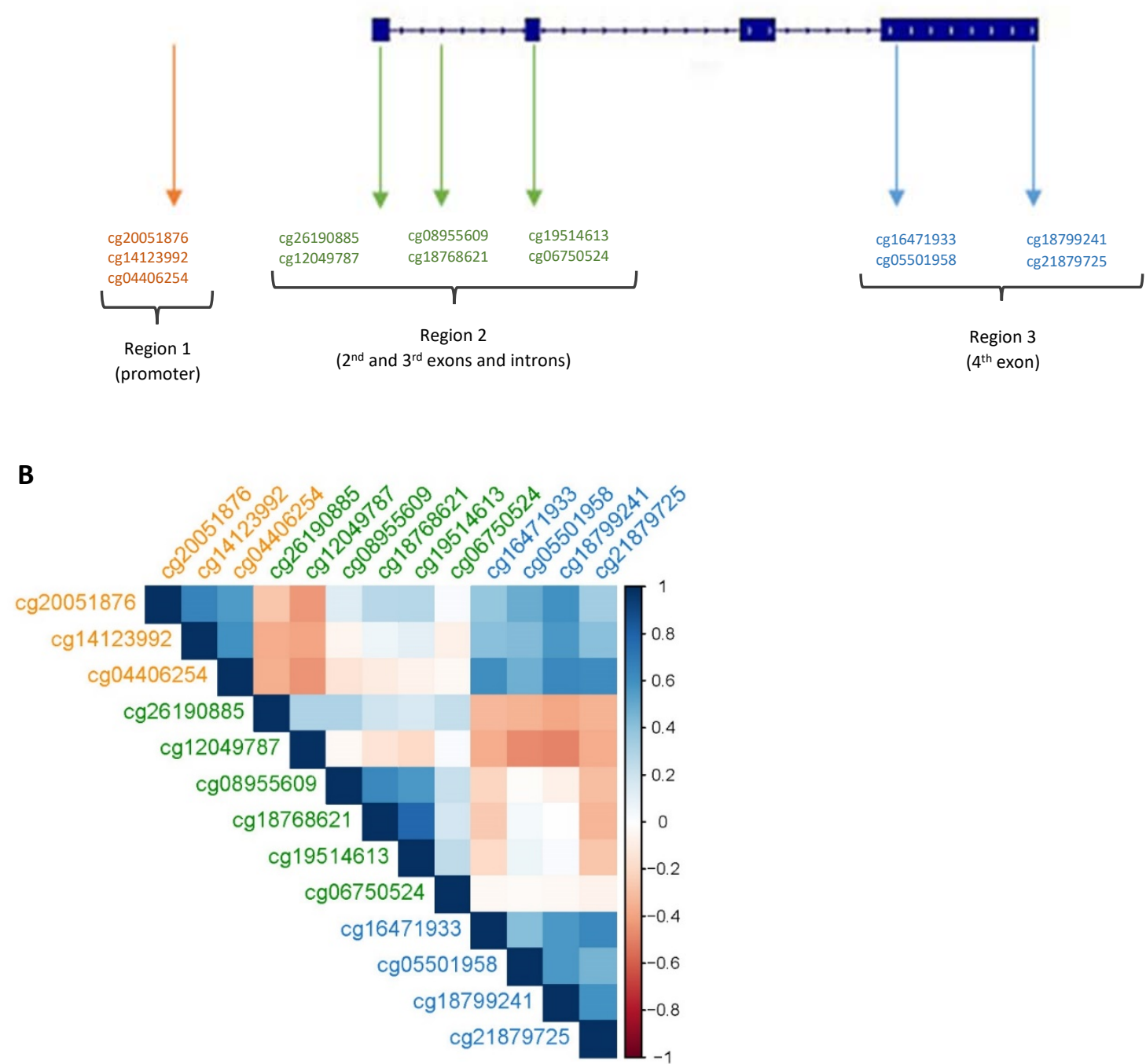


\section{Tables}

Table 1: Descriptive statistics and frequencies of genotypes and alleles/carriers in the sample.

\begin{tabular}{|c|c|c|c|}
\hline \multicolumn{2}{|l|}{ Trait } & Mean ${ }^{*}$ & $\mathbf{S D}^{\dagger}$ \\
\hline \multicolumn{2}{|l|}{ Age } & $53.0 *$ & $14.0^{*}$ \\
\hline \multicolumn{2}{|l|}{ Years in education $\ddagger$} & $4.0^{*}$ & $3.0^{*}$ \\
\hline \multicolumn{2}{|c|}{ Deprivation quintile $\S$} & $4.0^{*}$ & $3.0^{*}$ \\
\hline \multicolumn{2}{|c|}{ Processing speed (Wechsler digit symbol test) } & 71.2 & 15.6 \\
\hline \multicolumn{2}{|c|}{$\begin{array}{l}\text { Executive function (letter-based verbal } \\
\text { fluency test) }\end{array}$} & 41.1 & 11.7 \\
\hline \multicolumn{2}{|c|}{ Verbal ability (Mill Hill Vocabulary test) } & 30.1 & 4.5 \\
\hline \multicolumn{2}{|c|}{$\begin{array}{l}\text { Verbal declarative memory (Wechsler logical } \\
\text { memory test immediate and delayed) }\end{array}$} & 30.9 & 7.7 \\
\hline \multicolumn{2}{|c|}{ Heart rate (beats/minute) } & 63.7 & 10.3 \\
\hline \multicolumn{2}{|c|}{ Ratio of total-to-HDL cholesterol } & $3.7^{*}$ & $1.6^{*}$ \\
\hline \multicolumn{2}{|c|}{ Alcohol units per week } & $8.0^{*}$ & $12.0 *$ \\
\hline \multicolumn{2}{|l|}{ Trait } & $\mathbf{N}$ & $\%$ \\
\hline \multicolumn{2}{|l|}{ Sex (female) } & 3399 & 58.3 \\
\hline \multicolumn{2}{|c|}{$A D$ in close relatives } & 974 & 16.7 \\
\hline \multicolumn{2}{|c|}{ CVD in close relatives } & 3474 & 59.6 \\
\hline Genotype/carrier & $\%$ & \multicolumn{2}{|c|}{$\%$} \\
\hline$\varepsilon 2 / \varepsilon 2$ & 0.5 & \multicolumn{2}{|c|}{0.5} \\
\hline$\varepsilon 2 / \varepsilon 3$ & 11.4 & \multicolumn{2}{|c|}{11.4} \\
\hline$\varepsilon 2 / \varepsilon 4$ & 126 & \multicolumn{2}{|c|}{2.2} \\
\hline$\varepsilon 3 / \varepsilon 3$ & 3352 & \multicolumn{2}{|c|}{59.0} \\
\hline$\varepsilon 3 / \varepsilon 4$ & 1370 & \multicolumn{2}{|c|}{24.1} \\
\hline$\varepsilon 4 / \varepsilon 4$ & 156 & \multicolumn{2}{|c|}{2.7} \\
\hline$\varepsilon 2$-carrier & 12.2 & \multicolumn{2}{|c|}{12.2} \\
\hline$\varepsilon 3$-carrier & 3352 & \multicolumn{2}{|c|}{60.3} \\
\hline$\varepsilon 4$-carrier & 1526 & \multicolumn{2}{|c|}{27.5} \\
\hline \multicolumn{4}{|c|}{${ }^{*}$ The median is given when appropriate (denoted with *). } \\
\hline \multicolumn{4}{|c|}{ † The interquartile range is given when appropriate (denoted with *). } \\
\hline \multicolumn{4}{|c|}{$\begin{array}{l}\text { Ғ } 10 \text {-grade classification-system, where } 0: 0 \text { years, } 1: 1-4 \text { years, } 2: 5-9 \text { years, } 3: 10-11 \text { years, } 4: 12-13 \text { years, } 5: 14-15 \\
\text { years, } 6: 16-17 \text { years, } 7: 18-19 \text { years, } 8: 20-21 \text { years, } 9: 22-23 \text { years, } 10:>=24 \text { years. }\end{array}$} \\
\hline
\end{tabular}


Figure 2: Boxplots (left) and density plots (right) for differences in methylation levels between groups with different carrier-status. The statistically significant differences between groups after adjusting for multiple comparisons ( $p<0.0035)$ are denoted with asterisks. Depicted are only CpGs for which the fully-adjusted mixed linear models and post-hoc tests between carriers were significant after adjusting for multiple testing.

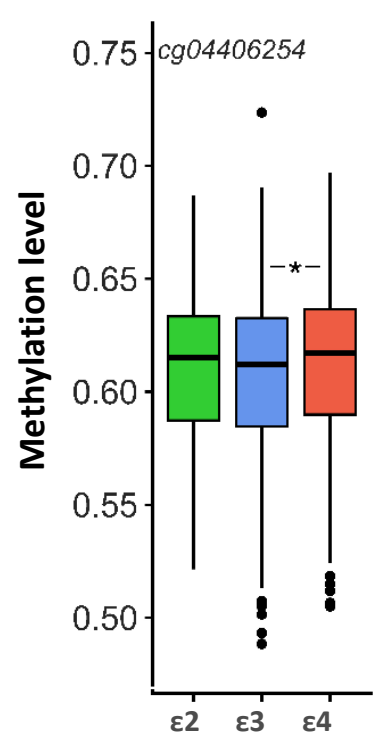

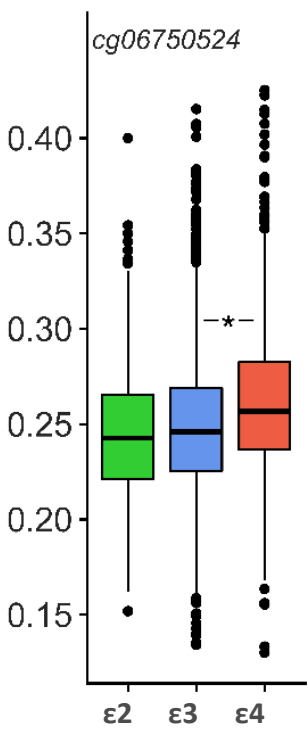

Carrier

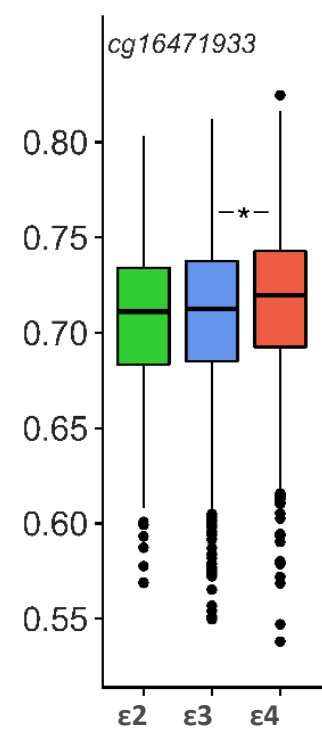

Carrier $\varepsilon 2 \square \varepsilon 3 \square$ $\varepsilon 4 \square$
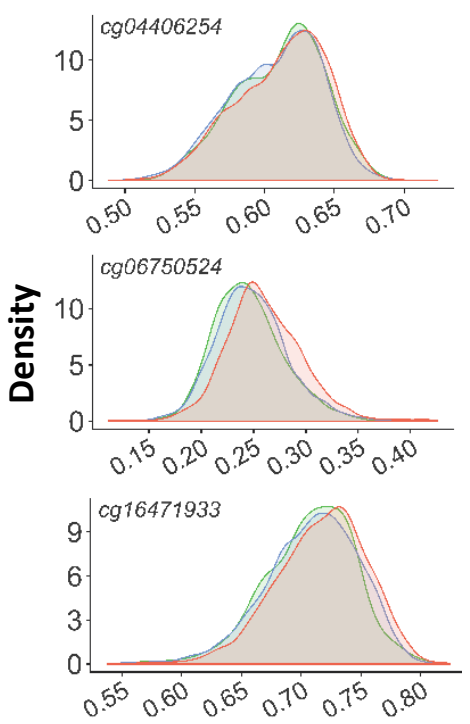

Methylation 
bioRxiv preprint doi: https://doi org/10 1101/811224 - this version posted October 21 2019. The copyriaht holder for this preprint (which was not certified by peer review) is the author/funder, who has granted bioRxiv a license to display the preprint in perpetuity. It is made available under aCC-BY-NC-ND 4.0 International license.

Figure 3: Relationship between age and methylation; the red line represents the linear fit between the two variables, the blue contour lines represent the density of the observations. Depicted are CpGs cg20051876, cg14123992, and cg18768621, for which the fully-adjusted mixed linear model was significant.

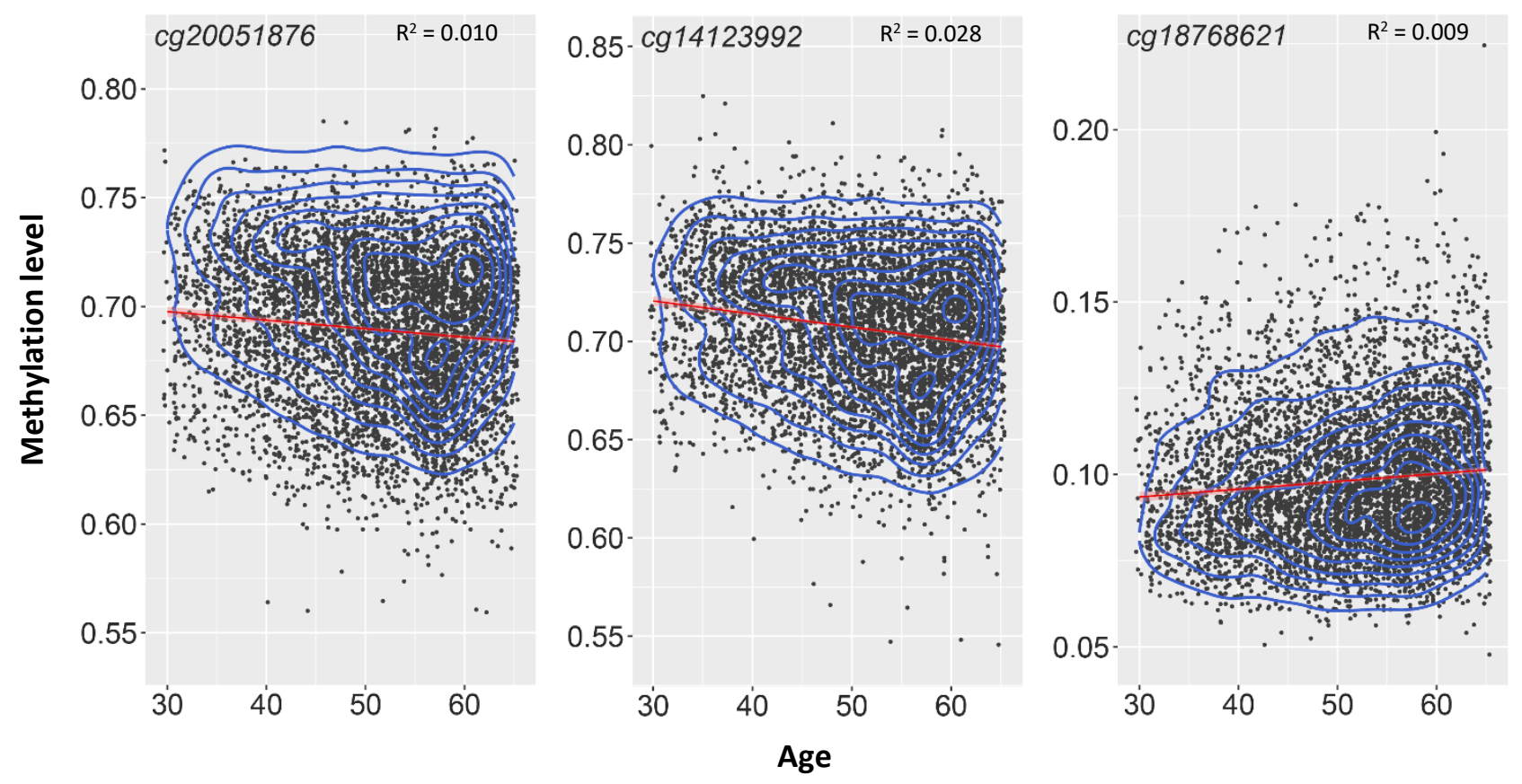


bioRxiv preprint doi: https://doi.org/10.1101/811224 this version posted October 21, 2019. The copyright holder for this preprint (which was not certified by peer review) is the author/funder, who has granted bioRxiv a license to display the preprint in perpetuity. It is made available under aCC-BY-NC-ND 4.0 International license.

Figure 4: Relationship between total-to-HDL cholesterol ratio and methylation. Depicted are CpGs cg08955609 and cg18768621, for which the linear models were significant.

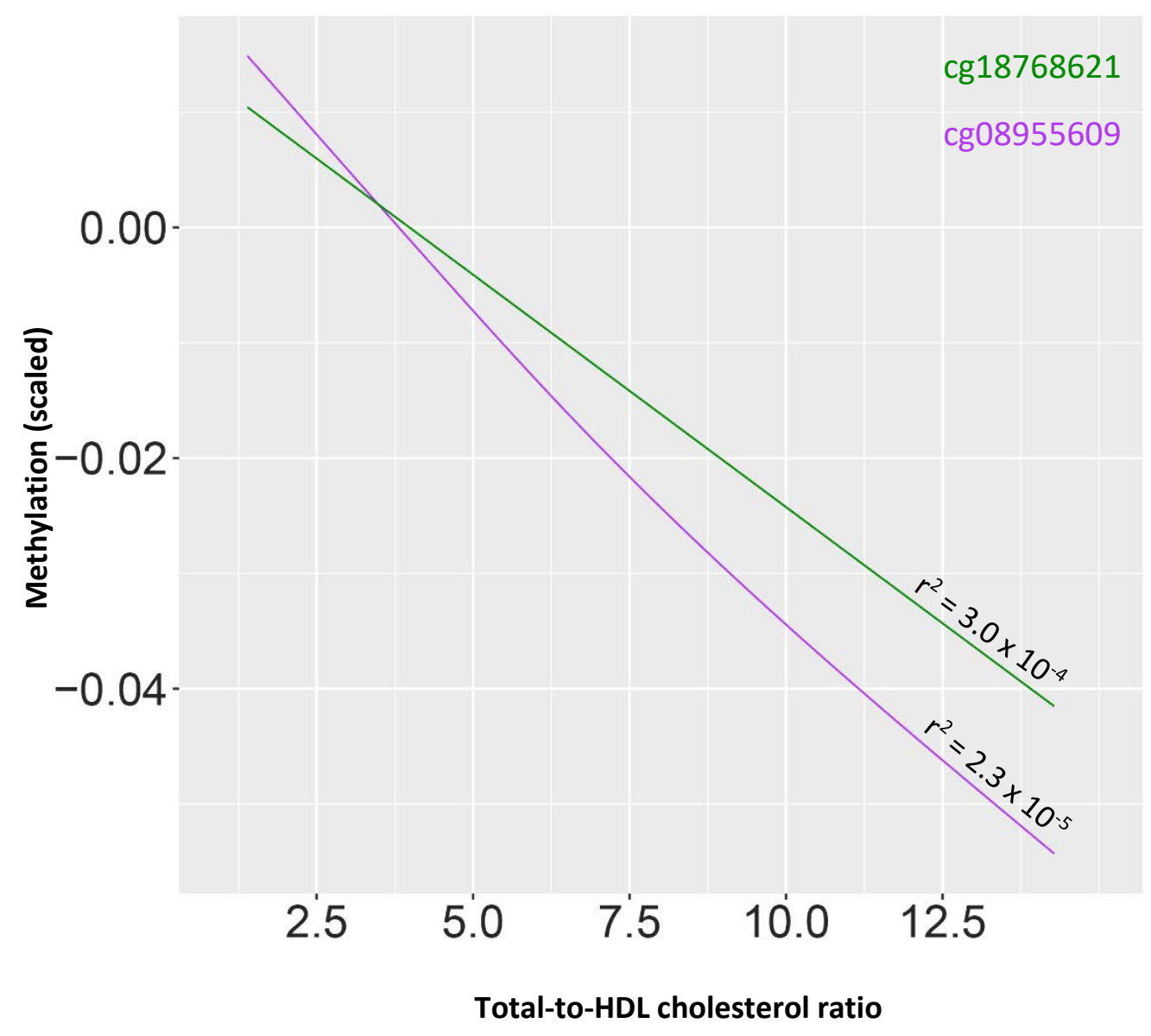




\section{References}

[1] Eichner JE, Dunn ST, Perveen G, Thompson DM, Stewart KE. Apolipoprotein E Polymorphism and Cardiovascular Disease : A HuGE Review. Am J Epidemiol 2002;155:487-95.

[2] Farrer LA, Cupples LA, Haines JL, Hyman B, Risch N, van Duijn CM. Effects of Age, Sex, and Ethnicity on the A Meta-analysis Genotype and Alzheimer Disease. JAMA 1997;93:303-11. doi:10.1007/s00339-008-4852-0.

[3] Genin E. APOE and Alzheimer's disease: A major gene with semi-dominant inheritance. Mol Psychiatry 2011;16:903-7. doi:10.1038/mp.2011.52.APOE.

[4] Fernández-Sanlés A, Sayols-Baixeras S, Subirana I, Degano IR, Elosua R. Association between DNA methylation and coronary heart disease or other atherosclerotic events: A systematic review. Atherosclerosis 2017;263:325-33. doi:10.1016/j.atherosclerosis.2017.05.022.

[5] Mahley RW. Apolipoprotein E: from cardiovascular disease to neurodegenerative disorders. J Mol Med 2016;94:739-46. doi:10.1007/s00109-016-1427-y.

[6] Davignon J, Gregg RE, Sing CF. Apolipoprotein E polymorphism and atherosclerosis. [Review]. Arteriosclerosis 1988;8:1-21. doi:10.1161/01.ATV.8.1.1.

[7] Forero DA, López-León S, González-Giraldo Y, Dries DR, Pereira-Morales AJ, Jiménez KM, et al. APOE gene and neuropsychiatric disorders and endophenotypes: A comprehensive review. Am J Med Genet Part B Neuropsychiatr Genet 2018;177:126-42. doi:10.1002/ajmg.b.32516.

[8] Giau V Van, Bagyinszky E, An SSA, Kim S. Role of apolipoprotein E in neurodegenerative diseases. Neuropsychiatr Dis Treat 2015;11:1723-37. doi:10.2147/NDT.S84266.

[9] Yu CE, Cudaback E, Foraker J, Thomson Z, Leong L, Lutz F, et al. Epigenetic signature and enhancer activity of the human APOE gene. Hum Mol Genet 2013;22:5036-47. doi:10.1093/hmg/ddt354.

[10] Ward H, Mitrou, Panagiota N, Bowman R, Luben R, Wareham NJ, Khaw K-T, et al. Genotype, Lipids, and Coronary Heart Disease Risk. Arch Intern Med 2009;169:1424-30.

[11] Delgado-Morales R. Neuroepigenomics in Aging and Disease. 2017. doi:10.1007/978-3-31953889-1.

[12] Lu H, Liu X, Deng Y, Qing H. DNA methylation, a hand behind neurodegenerative diseases. Front Aging Neurosci 2013;5:1-16. doi:10.3389/fnagi.2013.00085. 
[13] Lunnon K, Smith R, Hannon E, De Jager PL, Srivastava G, Volta M, et al. Methylomic profiling implicates cortical deregulation of ANK1 in Alzheimer's disease. Nat Neurosci 2014;17:116470. doi:10.1038/nn.3782.

[14] Foraker J, Millard SP, Leong L, Thomson Z, Chen S, Keene CD, et al. The APOE Gene is Differentially Methylated in Alzheimer's Disease. J Alzheimer's Dis 2015;48:745-55. doi:10.3233/JAD-143060.

[15] Karlsson IK, Ploner A, Wang Y, Gatz M, Pedersen NL, Hägg S. Apolipoprotein E DNA methylation and late-life disease. Int J Epidemiol 2018:899-907. doi:10.1093/ije/dyy025.

[16] Shao Y, Shaw M, Todd K, Khrestian M, D'Aleo G, Barnard PJ, et al. DNA methylation of TOMM40-APOE-APOC2 in Alzheimer's disease. J Hum Genet 2018;63:459-71. doi:10.1038/s10038-017-0393-8.

[17] Wang SC, Oeize B, Schumacher A. Age-specific epigenetic drift in late-onset Alzheimer's disease. PLoS One 2008;3. doi:10.1371/journal.pone.0002698.

[18] Chibnik. Alzheimer's loci: epigenetic associations and interaction with genetic factors. Ann Clin Transl Neurol 2015;2:636-47. doi:10.1002/acn3.201.

[19] Liu J, Zhao W, Ware EB, Turner ST, Mosley TH, Smith JA. DNA methylation in the APOE genomic region is associated with cognitive function in African Americans. BMC Med Genomics 2018;11:1-13. doi:10.1186/s12920-018-0363-9.

[20] Friso S, Pizzolo F, Choi SW, Guarini P, Castagna A, Ravagnani V, et al. Epigenetic control of 11 beta-hydroxysteroid dehydrogenase 2 gene promoter is related to human hypertension. Atherosclerosis 2008;199:323-7. doi:10.1016/j.atherosclerosis.2007.11.029.

[21] Khyzha N, Alizada A, Wilson MD, Fish JE. Epigenetics of Atherosclerosis: Emerging Mechanisms and Methods. Trends Mol Med 2017;23:332-47. doi:10.1016/j.molmed.2017.02.004.

[22] Ma Y, Smith CE, Lai CQ, Irvin MR, Parnell LD, Lee YC, et al. Genetic variants modify the effect of age on APOE methylation in the genetics of lipid lowering drugs and diet network study. Aging Cell 2015;14:49-59. doi:10.1111/acel.12293.

[23] Turunen MP, Aavik E, Ylä-Herttuala S. Epigenetics and atherosclerosis. Biochim Biophys Acta 2009;1790:886-891. doi:10.1016/j.bbagen.2009.02.008.

[24] Ji H, Zhou C, Pan R, Han L, Chen W, Xu X, et al. APOE hypermethylation is significantly 
associated with coronary heart disease in males. Gene 2019;689:84-9.

doi:10.1016/j.gene.2018.11.088.

[25] Smith BH, Campbell H, Blackwood D, Connell J, Connoer M, Deary IJ, et al. Generation Scotland: the Scottish Family Health Study; a new resource for researching genes and heritability. BMC Med Genet 2006;7:1-9. doi:10.1186/1471-2350-7-74.

[26] Smith BH, Campbell A, Linksted P, Fitzpatrick B, Jackson C, Kerr SM, et al. Cohort Profile: Generation Scotland: Scottish Family Health Study (GS:SFHS). The study, its participants and their potential for genetic research on health and illness. Int J Epidemiol 2013;42:689-700.

[27] Navrady LB, Deary IJ, Clarke T-K, McIntosh AM, Wardlaw JM, Murray AD, et al. Cohort Profile: Stratifying Resilience and Depression Longitudinally (STRADL): a questionnaire follow-up of Generation Scotland: Scottish Family Health Study (GS:SFHS). Int J Epidemiol 2017;47:13-14g. doi:10.1093/ije/dyx115.

[28] Madden RA, Mccartney DL, Walker RM, Hillary RF, Mairead L. Birth weight predicts psychiatric and physical health, cognitive function, and DNA methylation differences in an adult population. BioRxiv 2019.

[29] Lee SH, Yang J, Goddard ME, M. VP, Wray NR. Estimation of pleiotropy between complex diseases using single-nucleotide polymorphism-derived genomic relationships and restricted maximum likelihood. Bioinformatics 2012;28:2540-2. doi:10.1093/bioinformatics/bts474.

[30] McCartney DL, Stevenson AJ, Hillary RF, Walker RM, Bermingham, ML, Morris, SW, et al. Epigenetic signatures of starting and stopping smoking. EbioMedicine 2018;37:214-220. doi:10.1016/j.ebiom.2018.10.051.

[31] Kaushal A, Zhang H, Karmaus WJJ, Ray M, Torres MA, Smith AK, Wang SL. Comparison of different cell type correction methods for genome-scale epigenetics studies. BMC Bioinformatics 2017;18:216. doi:10.1186/s12859-017-1611-2.

[32] Singh PP, Singh M, Mastana SS. APOE distribution in world populations with new data from India and the UK. Ann Hum Biol 2006;33:279-308. doi:10.1080/03014460600594513.

[33] Braun PR, Han S, Hing B, Nagahama Y, Gaul LN, Heinzman JT, et al. Genome-wide DNA methylation comparison between live human brain and peripheral tissues within individuals. Transl Psychiatry 2019;9. doi:10.1038/s41398-019-0376-y.

[34] Edgar RD, Jones MJ, Meaney MJ, Turecki G, Kobor MS. BECon: A tool for interpreting DNA methylation findings from blood in the context of brain. Transl Psychiatry 2017;7:e1187-10. 
doi:10.1038/tp.2017.171.

[35] Hannon E, Lunnon K, Schalkwyk L, Mill J. Interindividual methylomic variation across blood, cortex, and cerebellum: Implications for epigenetic studies of neurological and neuropsychiatric phenotypes. Epigenetics 2015;10:1024-32.

doi:10.1080/15592294.2015.1100786.

[36] Slieker RC, van Iterson M, Luijk R, Beekman M, Zhernakova D V., Moed MH, et al. Age-related accrual of methylomic variability is linked to fundamental ageing mechanisms. Genome Biol 2016;17:1-13. doi:10.1186/s13059-016-1053-6.

[37] Lunnon K, Ibrahima Z, Proitsi P, Lourdusamy A, Newhouse S, Sattlecker M, et al. Mitochondrial dysfunction and immune activation are detectable in early alzheimer's disease blood. J Alzheimer's Dis 2012;30:685-710. doi:10.3233/JAD-2012-111592.

[38] De Jager PL, Srivastava G, Lunnon K, Burgess J, Schalkwyk LC, Yu L, et al. Alzheimer's disease: Early alterations in brain DNA methylation at ANK1, BIN1, RHBDF2 and other loci. Nat Neurosci 2014;17:1156-63. doi:10.1038/nn.3786.

[39] Sharma P, Kumar J, Garg G, Kumar A, Patowary A, Karthikeyan G, et al. Detection of Altered Global DNA Methylation in Coronary Artery Disease Patients. DNA Cell Biol 2008;27:357-65. doi:10.1089/dna.2007.0694.

[40] Villeneuve S, Brisson D, Gaudet D. Influence of Abdominal Obesity on the Lipid-Lipoprotein Profile in Apoprotein E2/4 Carriers: The Effect of an Apparent Duality. J Lipids 2015;2015:110. doi:10.1155/2015/742408. 